\title{
Analysis of alternation patterning in goldfish
}

\author{
P. A. COUVILLON and M. E. BITTERMAN \\ University of Hawaii, Honolulu, Hawaii 96822
}

\begin{abstract}
In Experiment 1, goldfish trained with alternation of reward (R) and nonreward (N) for responding to a single color gave clear evidence of patterning (more rapid responding on $R$ than on $\mathrm{N}$ trials). In Experiment 2, patterning was found for each of two colors alternately rewarded and nonrewarded in the sequence blue $R$, yellow $R$, blue $N$, yellow $N, \ldots$ Changes in performance with subsequent changes in the sequence of the two colors suggested that the patterning was based on carryover rather than on associative memory of $R$ and $N$.
\end{abstract}

That reward $(\mathrm{R})$ or nonreward $(\mathrm{N})$ for responding on one trial may serve as a cue to responding on a succeeding trial is perhaps demonstrated most directly by single-alternation patterning - the slower responding after $\mathbf{R}$ than after $\mathbf{N}$ that develops when $\mathbf{R}$ and $\mathrm{N}$ trials are regularly alternated (Tyler, Wortz, \& Bitterman, 1953). In massed trials, it seems reasonable to assume that the animals can make use of aftereffects of $\mathbf{R}$ and $\mathbf{N}$ that are carried over from trial to trial (Hull, 1952; Sheffield, 1949); the aftereffects may be stimuli, such as the taste of food remaining in the mouth or feedback from persisting emotional response to $\mathrm{N}$, and they may be stimulus traces (in Hull's sense) or short-term memories-continuously decaying, residual effects of prior stimulation. An alternative interpretation suggested by patterning effects in spaced trials rests on the concept of reinstatement; the animals are assumed to rely on associative memories of $\mathbf{R}$ and $\mathbf{N}$ evoked by stimuli previously paired with them (Capaldi, 1971). The carryover and reinstatement interpretations are not incompatible, of course, and it is possible that both mechanisms operate in massed trials.

To demonstrate that single-alternation patterning in massed trials may be based on reinstatement, as distinct from carryover, Capaldi (1971) trained rats in a runway that was sometimes black and sometimes white, with single alternation of color and double alternation of $R$ and $N$-black $R$, white $R$, black $N$, white $N, \ldots$ Patterning developed both in black and white, which Capaldi attributed to associative memory on black trials of what had last happened in black, and on white trials of what had last happened in white. As Pavlik and Collier (1975) have noted, however, the patterning produced by Capaldi's procedure does not unequivocally demonstrate reinstatement. While $\mathbf{R}$ or $\mathbf{N}$ on Trial $\mathbf{T}$ is not predictable solely on the basis of carryover from $R$ or $N$ on Trial $T-1$, it is predictable on the basis of carryover from $\mathrm{R}$ or $\mathrm{N}$

\footnotetext{
This research was supported by Grant MH33077 from NIMH. Requests for reprints may be addressed to the Békésy Laboratory of Neurobiology, East-West Road, Honolulu, Hawaii 96822.
}

on Trial $\mathrm{T}-1$ in compound with color on Trial $\mathrm{T}$ (responding to white is rewarded after $\mathrm{R}$ but not after $\mathrm{N}$, and responding to black is rewarded after $\mathrm{N}$ but not after R). The carryover interpretation is supported by Pavlik and Collier's results for rats trained like Capaldi's and then tested with a simple variation of the schedule-black R, white N, black N, white R. The change produced a disruption in performance predicted in terms of carryover but not in terms of reinstatement.

The same general method was used here to analyze single-alternation patterning in goldfish. In reviewing the comparative data, Mackintosh (1974) concluded that the behavior of goldfish is "less readily controlled by traces of the outcomes of preceding trials" than is the behavior of rats (p. 402), a formulation which blurs the distinction between reinstatement and carryover. Our hypothesis, based on such findings as that goldfish show the partial reinforcement effect in massed trials (Gonzalez \& Bitterman, 1967) but not in spaced trials (Schutz \& Bitterman, 1969), is that their behavior is strongly controlled by carryover but not at all by reinstatement. Variations of Capaldi's procedure make it possible to look for both effects in massed trials.

\section{EXPERIMENT 1}

The purpose of the first experiment was simply to establish a single-alternation pattern for subsequent analysis and to examine some of its temporal characteristics. Previous attempts to demonstrate singlealternation patterning in goldfish often have been unsuccessful, as Mackintosh (1974) has noted, but there is some question regarding the adequacy of the conditions that have been used (Gonzalez, 1972). In our attempt, we take account of the finding for rats that patterning is enhanced when reward is large and when repetitive responding is measured (Gonzalez, Bainbridge, \& Bitterman, 1966).

\section{Method \\ Subjects and Apparatus. The subjects, eight $10-\mathrm{cm}$ goldfish,}


were well adapted to laboratory conditions. Their living enclosures and their training enclosures belonged to the same open system, the water of which was continuously replaced. The training enclosures were designed so that any unconsumed residues of the liquid food used as reward were carried away immediately in the outflow. For the training, the target-striking technique developed in this laboratory was used (for details see Amiro \& Bitterman, 1980; Brandon \& Bitterman, 1979). The target was an illuminated 4-cm Plexiglas disk, with a nipple in its center through which liquid food was pumped, and contact with the target was the recorded response.

Procedure. The discrete-trials/fixed-interval training method of Woodard and Bitterman (1974) was employed. Each daily training session consisted of a series of 40 trials separated by an intertrial interval of $10 \mathrm{sec}$ in darkness. The odd-numbered trials were rewarded, and the even-numbered trials nonrewarded. At the start of each trial, the target was illuminated with blue light. There was an initial 20-sec period during which responses to the target were counted but had no programmed consequence, and then the counting stopped, although the target continued to be illuminated. On $R$ trials, the next response produced a drop of food and initiated a 10-sec reinforcement period during which each further response produced another drop of food; at the end of the reinforcement period, the blue light was turned off, the feeder was disconnected, and the next intertrial interval began. On $\mathrm{N}$ trials, a 10-sec penalty timer started after the initial 20 -sec period, and each subsequent response reset the penalty timer, which had to time out before the trial could end. The procedure was fully automated. After 15 days of training under these conditions, the intertrial interval was increased from 10 to $30 \mathrm{sec}$ for 1 day, and then to $1 \mathrm{~min}$ for the next 7 days.

\section{Results}

Having been pretrained in a series of consistently reinforced trials, the animals responded at a high rate on both $\mathbf{R}$ and $\mathbf{N}$ trials at the outset of the training, but as the alternation training continued, the rate of responding on even-numbered $(\mathrm{N})$ trials declined progressively. For all 15 days of training, the difference in rate of responding on $\mathbf{R}$ and $\mathbf{N}$ trials was highly significant $[F(1,7)=25.80, p=.0014]$, as was the interaction of the R-N Difference by Days $[F(14,98)=$ $7.41, \mathrm{p}<.0001]$. Pooled within-sessions curves for the last 4 days of training with the $10-\mathrm{sec}$ intertrial interval are plotted in the left-hand portion of Figure 1 . The curves show clear patterning that tended to be lost in the interval between sessions but was

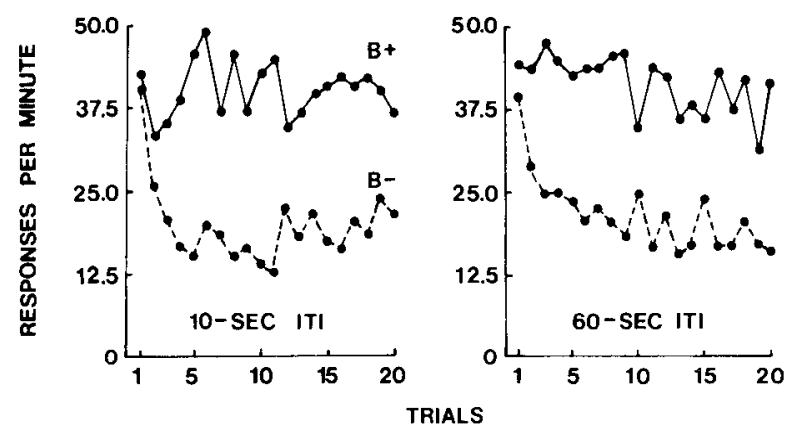

Figure 1. Asymptotic within-sessions performance in Experiment 1 for intertrial intervals of 10 and $60 \mathrm{sec}$. rapidly restored when training resumed. The interaction of the R-N Difference by Trials Within Sessions in the overall analysis was highly significant $[F(19,133)$ $=2.84, \mathrm{p}=.0002]$. The within-sessions curves also seem to show that the patterning was based on slowing after $\mathbf{R}$ rather than speeding after $\mathbf{N}$, although the possibility that a greater functional symmetry was masked by a performance ceiling should not be overlooked. The results are very much the same as those for pigeons studied under directly analogous conditions (Couvillon, Brandon, Woodard, \& Bitterman, 1980).

When the intertrial interval was increased to $30 \mathrm{sec}$, the alternation pattern was unaffected, and the further increase to $1 \mathrm{~min}$ produced only a transitional disturbance. Analysis of variance in the data for all 7 days of training with the 1-min intertrial interval yielded a highly significant difference in rate of responding on $R$ and $N$ trials $[F(1,7)=31.49, p=.0008]$. The pooled within-sessions curves for the last 4 days at $1 \mathrm{~min}$, which are plotted in the right-hand portion of Figure 1, resemble rather closely the adjacent 10sec curves. Slowing after $R$ again seemed to be responsible for the patterning, which tended to be lost in the interval between sessions but recovered rapidly when training resumed. The interaction of the R-N Difference by Trials Within Sessions in the overall analysis was again significant $[\mathrm{F}(19,133)=2.65, \mathrm{p}=.0006]$.

\section{EXPERIMENT 2}

Robust single-alternation patterning in goldfish having been demonstrated, an inquiry into its basis was planned. The approach was first to try to establish the concurrent two-color patterning previously found in rats, and then, if the attempt was successful, to vary the schedule in ways designed to distinguish between carryover and reinstatement.

\section{Method}

Subjects and Apparatus. The subjects were those used in the first experiment, except for one that became ill in the course of the extended training and whose data therefore were eliminated. The same apparatus was used.

Procedure. In six pretraining sessions, the single-alternation schedule with blue was continued, but the intertrial interval was reduced again to $10 \mathrm{sec}$-the interval to be used in the subsequent two-stimulus training.

The first stage of that training lasted 30 days. There were 40 trials per session, with a blue (B) target on odd-numbered trials, a yellow (Y) target on even-numbered trials, and double alternation of $R$ and $N$. Thus, the sequence was $B-R, Y-R, B-N, Y-N, \ldots$ In the second stage, there were 28 sessions under the same conditions, except that the schedule was changed to $Y-R, B-R, Y-N$, B-N, .... Note that the single alternation of $B$ and $Y$ continued, as did the double alternation of $R$ and $N, R$ and $N$ trials with each color being alternated regularly just as before. Then the number of trials per session was increased from 40 to 60 for 12 additional sessions in preparation for a more complicated schedule to follow. In the 17 sessions of the third stage, the two colors were not alternated, but presented in quasi-random sequences, although $\mathbf{R}$ and $\mathbf{N}$ trials with each color continued to be alternated. The se- 
quences (Order 1: B-R, B-N, Y-R, B-R, Y-N, B-N, Y-R, Y-N, B-R B-N, Y-R, Y-N, Y-R, B-R, Y-N, Y-R, B-N, B-R, Y-N, B-N ; Order 2: Y-R, Y-N, B-R, B-N, Y-R, Y-N, Y-R, B-R, Y-N, Y-R, B-N, B-R, Y-N, B-N, B-R, B-N, Y-R, B-R, Y-N, B-N) were such that, on a $Y$ trial, $R$ or $N$ was predictable from $R$ or $N$ on the immediately preceding trial ( $R$ after $N$ and $N$ after $R$ ) as well as from $\mathbf{R}$ or $\mathbf{N}$ on the preceding trial with $\mathbf{Y}$. On a $\mathbf{B}$ trial, by contrast, $\mathbf{R}$ or $\mathbf{N}$ was predictable only from $\mathbf{R}$ or $\mathbf{N}$ on the preceding $\mathbf{B}$ trial; the interest here was to examine the possibility of control by associative memory of $\mathbf{R}$ and $\mathbf{N}$ in the absence of potentially masking carryover cues.

\section{Results}

From the outset of training in the first stage (B-R, Y-R, B-N, Y-N, ...), the animals showed some appropriate patterning in $B$ (higher rates on $R$ than on $\mathrm{N}$ trials), which may have reflected a tendency, established in the previous training with $B$ alone, to respond on the basis of carryover from $R$ or $\mathrm{N}$ on the immediately preceding trial. In $\mathrm{Y}$, they showed reverse patterning to begin with (higher rates on $\mathrm{N}$ trials), which can be explained in the same way because $Y-N$ followed $N$ and $Y-R$ followed $R$. The reverse patterning in $\mathrm{Y}$ disappeared by the fourth session and was gradually replaced by appropriate patterning, which did not, however, become quite as marked as the patterning in B. An analysis of variance based on the data for all 30 days showed a highly significant difference in rate on $R$ and $N$ trials $[F(1,6)$ $=65.98, p=.0002]$, as well as an interaction of the R-N Difference by Color $[F(1,6)=15.96, p=.0072]$. Asymptotic within-sessions performance in this phase (based on pooled data for the last six sessions) is plotted in the first panel of Figure 2. The better patterning in $\mathrm{B}$ than in $\mathrm{Y}$ may have been due to a general tendency to respond more rapidly after $\mathrm{N}$ than after $\mathrm{R}-\mathrm{a}$ local contrast effect that facilitated alternation patterning in B but opposed it in Y.

With the shift to the schedule of the second stage (Y-R, B-R, Y-N, B-N, ...), performance was dis-

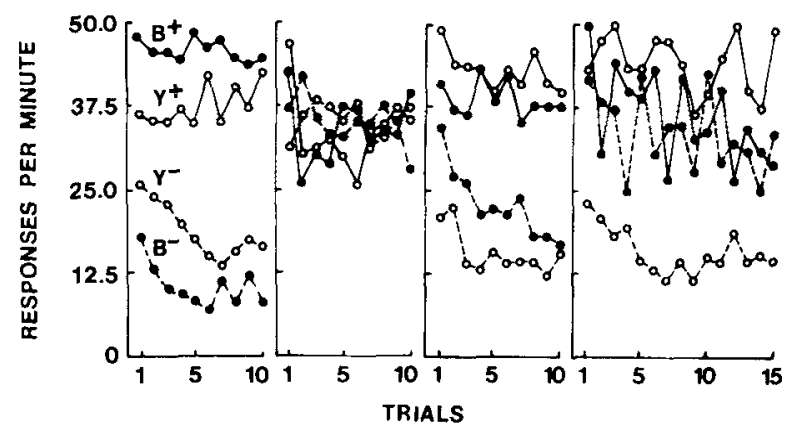

Figure 2. Performance in Experiment 2. First pancl: Asymptotic performance in the first stage (B-R, Y-R, B-N, Y-N, ...). Second panel: Disruption of performance in the early sessions of the second stage (Y-R, B-R, Y-N, B-N, ...). Third panel: Asymptotic performance in the second stage. Fourth panel: Asymptotic performance in the third stage, in which patterning for both colors is predicted by associative memory, but patterning only for $\mathrm{Y}$ is predicted by carryover. rupted. Pooled within-sessions curves based on the data of the first three postshift sessions are plotted in the second panel of Figure 2. On the assumption that patterning in the first stage was based on reinstatement, the disruption is difficult to understand, because memory on a given trial of what happened on the preceding trial with the same color would continue in the same way as before to predict outcome, remembered $R$ predicting $\mathrm{N}$ and remembered $\mathrm{N}$ predicting $R$ in both stages. If, however, patterning in the first stage was based on compounds of the color presented on any trial and carryover from $\mathrm{R}$ or $\mathrm{N}$ on the immediately preceding trial, disruption would be expected, because predictions based on the compounds were reversed in the second stage-for example, $B$ plus carryover from $\mathbf{R}$ predicted $\mathbf{N}$ in the first stage but $R$ in the second-and there was some indication of reverse patterning in the early trials. As training continued, appropriate patterning gradually was restored, although performance was better for $\mathrm{Y}$ than for $\mathrm{B}$ in that the $\mathrm{R}-\mathrm{N}$ difference for $\mathrm{Y}$ grew more rapidly and was greater at asymptote. Analysis of variance based on the data for the 28 sessions in the second stage showed a significant $R-N$ difference $[F(1,6)=132.03, p<.0001]$, as well as a significant interaction of the R-N Difference by Color $[F(1,6)=$ $6.42, p=.044]$. Asymptotic within-sessions curves (based on the pooled data for the last six sessions of the second stage) are plotted in the third panel of Figure 2. The poorer performance for $B$ than for $Y$ again may be attributed to a general tendency to respond at a higher rate after $\mathbf{N}$ than after $\mathbf{R}$, since B-R now followed $R$ and B-N followed N, while $Y-R$ now followed $\mathrm{N}$ and $\mathrm{Y}-\mathrm{N}$ followed $\mathrm{R}$.

In the third stage, $R$ or $N$ on a $Y$ trial continued to be predictable both on the basis of associative memory of $\mathrm{R}$ or $\mathrm{N}$ on the preceding $\mathrm{Y}$ trial and on the basis of carryover from $\mathrm{R}$ or $\mathrm{N}$ on the immediately preceding trial irrespective of color. On a $B$ trial, however, $\mathrm{R}$ or $\mathrm{N}$ was no longer predictable on the basis of carryover, and the fact that patterning on $\mathrm{Y}$ trials continued while patterning on B trials did not points again to patterning based on carryover. Analysis of variance for the data of all 17 sessions yielded a significant R-N difference $[F(1,6)=52.25, p=.0004]$ and a significant interaction of the R-N Difference by Color $[F(1,6)=54.73, p=.0003]$. The asymptotic within-sessions pattern (based on pooled data for the last six sessions of the third stage) is plotted in the fourth panel of Figure 2. The curves for $\mathrm{Y}+$ and $\mathrm{Y}-$ are widely separated, as before, but the curves for $\mathrm{B}+$ and $\mathrm{B}-$ cross and recross each other, giving no indication of discrimination.

\section{DISCUSSION}

These experiments provide clear evidence of singlealternation patterning in goldfish, not only in train- 
ing with one color (Experiment 1), but also in training with two colors concurrently (Experiment 2). The second experiment also provides clear evidence that the patterning is based on carryover rather than on reinstatement. The dependence on carryover is shown by the results of the second stage, and the insufficiency of associative memory (if any) by the results of the third stage. It should be recognized, of course, that the alternation experiment constitutes what may well be the severest test of the theory that associative memories of $\mathbf{R}$ or $\mathbf{N}$ may acquire discriminative control of responding in goldfish. For alternation to occur, the associations between color and $\mathrm{R}$ or $\mathrm{N}$ (on which the memories presumably are based) must change in strength very rapidly (Couvillon et al., 1980). An association between one color (say, B) and $R$ that is strong enough to evoke a salient memory of $R$ when $B$ next occurs must give place after a single $\mathrm{N}$ trial with $\mathrm{B}$ to an association between $\mathrm{B}$ and $\mathrm{N}$ that is strong enough to evoke a salient memory of $\mathrm{N}$ when B next occurs, whereupon, in consequence of $R$ on that trial, the association of $B$ with $R$ must become dominant once more, and so forth. In our recent work with pigeons (Couvillon et al., 1980), singlealternation patterning was found under conditions like those used here in Experiment 1, but the patterning disappeared when trials with other colors were interpolated in such a way as to prevent prediction based on carryover. Other patterning effects, including the partial reinforcement effect, did, however, survive the introduction of interpolated trials, requiring the assumption that associative memory of $\mathrm{N}$ may, under certain circumstances, acquire discriminative control of responding in pigeons. Analogous experiments with goldfish should be instructive. The present results do, however, underscore the importance of the distinction between control by carryover (which is demonstrated) and control by reinstatement (which is not).

\section{REFERENCES}

Amiro, T. W., \& Bitterman, M. E. Second-order appetitive conditioning in goldfish. Journal of Experimental Psychology: Animal Behavior Processes, 1980, 6, 41-48.

Brandon, S. E., \& Bitterman, M. E. Analysis of autoshaping in goldfish. Animal Learning \& Behavior, 1979, 7, 57-62.

CAPAldi, E. J. Memory and learning: A sequential viewpoint. In W. K. Honig \& P. H. R. James (Eds.), Animal memory. New York: Academic Press, 1971.

Couvillon, P. A., Brandon, S. E., Woodard, W. T., \& Bitterman, M. E. Performance of pigeons in patterned sequences of rewarded and nonrewarded trials. Journal of Experimental Psychology: Animal Behavior Processes, 1980, 6, 137-154.

Gonzalez, R. C. Patterning in goldfish as a function of magnitude of reinforcement. Psychonomic Science, 1972, 28, 53-55.

Gonzalez, R. C., Bainbridge, P., \& Bitterman, M. E. Discretetrials lever-pressing in the rat as a function of pattern of reinforcement, effortfulness of response, and amount of reward. Journal of Comparative and Physiological Psychology, 1966, 61, 110-122.

Gonzalez, R. C., \& Bitterman, M. E. Partial reinforcement effect in the goldfish as a function of amount of reward. Journal of Comparative and Physiological Psychology, 1967, 64, 163-167.

Hult, C. L. A behavior system. New Haven, Conn: Yale University Press, 1952.

MaCkintosh, N. J. The psychology of animal learning. London: Academic Press, 1974.

Pavlik, W. B., \& Collien, A. C. An analysis of "signaled doublealternation patterning" in the rat. Animal Learning \& Behavior, $1975,3,73-75$.

Schutz, S. L., \& Bitterman, M. E. Spaced-trials partial reinforcement and resistance to extinction in the goldfish. Journal of Comparative and Physiological Psychology, 1969, 68, 126-128.

Sheffield, V. F. Extinction as a function of partial reinforcement and distribution of practice. Journal of Experimental Psychology, 1949, 39, 511-526.

Tyler, D. W., Wortz, E. C., \& Bitterman, M. E. The effect of random and alternating partial reinforcement on resistance to extinction in the rat. American Journal of Psychology, 1953, 66, 57-65.

Woodard, W. T., \& Bitterman, M. E. A discrete-trials/fixedinterval method of discrimination training. Behavior Research Methods \& Instrumentation, 1974, 6, 389-392.

(Received for publication July 18, 1980; revision accepted November 10,1980 .) 